\title{
A Comparative Study between Electrocautery and Steel Scalpel in Making Abdominal Skin Incisions
}

\author{
Dr. Dorendro Thingujam ${ }^{1}$, Dr. Ksh. Raju Singh ${ }^{2}$, Dr. Pritam Das ${ }^{1}$, \\ Dr. H. Parasmani Mangang ${ }^{1}$, Dr. Christo Cyriac Thomas ${ }^{1}$, Dr. S. Ranita Devi ${ }^{3}$. \\ ${ }^{1}$ (PGT, Deptt. Of General Surgery, Regional Institute Of Medical Sciences, Imphal, Manipur, India, 795004). \\ ${ }^{2}$ (Assistant Professor, Deptt. Of General Surgery, Regional Institute Of Sciences, Imphal, Manipur, India, \\ 795004). \\ ${ }_{3}^{3}$ (Professor, Deptt. Of General Surgery, Regional Institute Of Medical Sciences, Imphal, Manipur, 795004).
}

\begin{abstract}
:
Background: Electrocautery is commonly used in surgical practice. However its use has been limited in skin due to the fear of tissue scarring, impaired wound healing and wound infection due to damaged tissue.

Objectives: To evaluate and compare the use of electrocautery and steel scalpel in making abdominal skin incisions with regard to operating time, postoperative wound complication rate and the duration of hospital stay.

Materials and Methods: The study was a prospective randomized type conducted in the Department of Surgery, Regional Institute of Medical Sciences (RIMS), Imphal. 100 patients undergoing open cholecystectomy were divided into two groups, scalpel group in which skin incision was made with steel scalpel, and cautery group with electrocautery. Comparison was made between the two groups based on the above objectives.

Results: In this study, we find that the operating time, rates of wound complication and the duration of hospital stay were comparable between the two groups.

Conclusion: The study demonstrates that electrocautery can be used as an alternative to steel scalpel for making abdominal skin incisions.
\end{abstract}

Keywords: Electrocautery, Steel scalpel, cholecystectomy, skin incision.

\section{Introduction}

Very few operations can be performed without cutting through the skin. It may be incised to gain access to deeper structures, or the surgery may be primarily on the skin itself whether for the repair of trauma or for the excision of a skin lesion. ${ }^{1}$ Skin bleeding is the problem after starting surgery. ${ }^{2}$ Traditionally scalpels with disposable knives are used for skin incisions. Electrocautery has been used less frequently because of the fear of tissue damage leading to more postoperative pain, impaired wound healing and hypertrophic scarring. ${ }^{3}$

Electrosurgical incision of diathermy type is not a true cutting incision. This method heats cells within the tissue so rapidly that they vaporize, leaving a cavity within the cell matrix. The heat created dissipates as steam rather than being transmitted into adjacent tissues. As the electrode is moved forward, new cells are contacted and vaporized with the creation of the incision. This may explain the absence of tissue charring and the subsequent healing of tissues with minimal scarring. ${ }^{4}$

Cutting diathermy incises skin with little charring and necrosis compared with coagulation diathermy, which generates heat more slowly via an interrupted current output. The use of thermal energy, of either type, raises concerns about collateral heat damage, impaired wound healing and a possible increased risk of wound infection secondary to necrosis at the wound edges. ${ }^{5,6}$

Studies conducted in humans and animals have provided different results. Therefore this study was taken up to compare the two and to substantiate the results of studies conducted earlier.

\subsection{Source of data:}

\section{Materials And Method}

One hundred patients admitted at Regional Institute of Medical Sciences (RIMS) Hospital, Imphal, Manipur, India, over a 2 year period from September 2013 to September 2015 requiring routine subcostal incisions for cholecystectomy fulfilling the eligibility criteria were included in this study. This sample size is according to availability of cases admitted in RIMS hospital. The study was done after getting due approval from the Institutional Ethics Committee, RIMS Hospital.

\subsection{Inclusion criteria:}


Any patient in the age group of 15-70 years requiring routine subcostal incisions for cholecystectomy were included in this study irrespective of sex, race, religion, place of origin or socio-economic status.

\subsection{Exclusion Criteria:}

a) Patients requiring incisions to be made over previous surgical scars.

b) Patients on anti-coagulant therapy. f) Uncontrolled diabetes and hypertension.

c) Pregnancy.

d) Emergency surgeries.

e) Severe organ dysfunctions.

g) Immunocompromised status.

h) Patients $<15$ years and $>70$ years.

i) Patients not willing to participate in the study.

\subsection{Method}

100 patients undergoing elective open cholecystectomy for cholelithiasis were randomized prospectively to either scalpel or electrocautery group for skin incision. In $50 \%$ of the cases, skin incision was given by cutting-mode high frequency electrocautery and in the remaining 50\%, it was done by scalpel (Fig. 5 and 6). Electrocautery was used to cut deeper structures in both the groups. Both groups were compared with respect to operating time, postoperative wound complication rates and the duration of hospital stay.

\subsection{Data Analysis:}

The analysis of data collected was done by statistical software namely SAS 9.2, SPSS 15.0, Stata 10.1, MedCalc 9.0.1,Systat 12.0 and R environment ver.2.11.1 and Microsoft word and Excel were used to generate graphs, tables etc . Descriptive and inferential statistical analyses were carried out in the study. Student t test (two tailed, independent) and Chi-square/ Fisher Exact test were used to find the significance of study parameters on continuous and categorical scale respectively

\section{Results}

Although the mean operating time was less in the electrocautery group as compared to scalpel group (46.84 \pm 3.01 versus $47.44 \pm 2.51$ ), the difference was found to be statistically insignificant with a $\mathrm{P}$ value of 0.281 (Table 1). The length of skin incision was also shorter in electrocautery group $(6.28 \pm 0.38$ versus $6.33 \pm 0.31)$ but this difference was statistically insignificant $(\mathrm{P}=0.455)$. Similarly the incidence of postoperative complications was less in electrocautery group with 4 patients developing complications in the electrocautery group whereas 8 patients had complications in the scalpel group. However the difference was also found to be statistically insignificant as $\mathrm{P}=0.392$ (Table 2). In the same way, although the mean duration of hospital stay was lesser in the electrocautery group $(5.06 \pm 0.68$ versus $5.26 \pm 0.85)$, the difference was found to be statistically insignificant with a $\mathrm{P}$ value of 0.198 (Table 3).

Majority of the patients operated in our study $(85 \%)$ were female patients. $83 \%$ of the patients were in the age group of 20-50 years with the maximum patients(34) being in the age group of 30-40 years. The mean age of the study was $40.04 \pm 10.84$ years.

Table 1: Comparison of operating time

\begin{tabular}{|l|l|l|l|}
\hline $\begin{array}{l}\text { Duration of operation (in } \\
\text { minutes) }\end{array}$ & \multicolumn{2}{|l|}{ Mode of incision- Scalpel or Cautery } & \multirow{2}{*}{ Total } \\
\cline { 2 - 4 } & Scalpel & Cautery & \\
\hline$<48$ & $19(38 \%)$ & $23(46 \%)$ & $42(42 \%)$ \\
\hline $48-56$ & $31(62 \%)$ & $27(54 \%)$ & $58(58 \%)$ \\
\hline$>56$ & $0(0 \%)$ & $0(0 \%)$ & $0(0 \%)$ \\
\hline Total & $50(100 \%)$ & $50(100 \%)$ & $100(100 \%)$ \\
\hline
\end{tabular}

$$
\mathrm{P}=0.544
$$

Table 2: Comparison of post-operative complications

\begin{tabular}{|l|l|l|l|}
\hline Post-operative complications- & Mode of incision- Scalpel or Cautery & \multirow{2}{*}{ Total } \\
\cline { 3 - 4 } $\begin{array}{l}\text { None, seroma,hematoma or } \\
\text { purulent }\end{array}$ & Scalpel & Cautery & \\
\hline No complications & $42(84 \%)$ & $46(92 \%)$ & $88(88 \%)$ \\
\hline Seroma & $4(8 \%)$ & $1(2 \%)$ & $5(5 \%)$ \\
\hline Purulent & $3(6 \%)$ & $1(2 \%)$ & $4(4 \%)$ \\
\hline Hematoma & $1(2 \%)$ & $2(4 \%)$ & $3(3 \%)$ \\
\hline Total & $50(100 \%)$ & $50(100 \%)$ & $100(100 \%)$ \\
\hline
\end{tabular}

Table 3: Comparison of post-operative hospital stays

\begin{tabular}{|l|l|l|l|}
\hline \multirow{2}{*}{$\begin{array}{l}\text { Post operative hospital stay } \\
\text { (in days) }\end{array}$} & Mode of incision- Scalpel or Cautery & \multirow{2}{*}{ Total } \\
\cline { 2 - 3 } & Scalpel & Cautery & \\
\hline 4 & $7(14 \%)$ & $9(18 \%)$ & $16(16 \%)$ \\
\hline
\end{tabular}




\begin{tabular}{|l|l|l|l|}
\hline 5 & $28(56 \%)$ & $30(60 \%)$ & $58(58 \%)$ \\
\hline 6 & $11(22 \%)$ & $10(20 \%)$ & $21(21 \%)$ \\
\hline 7 & $3(6 \%)$ & $1(2 \%)$ & $4(4 \%)$ \\
\hline 8 & $1(2 \%)$ & $0(0 \%)$ & $1(1 \%)$ \\
\hline Total & $50(100 \%)$ & $50(100 \%)$ & $100(100 \%)$ \\
\hline Mean \pm SD & $5.26 \pm 0.85$ & $5.06 \pm 0.68$ & $5.16 \pm 0.77$ \\
\hline
\end{tabular}

$\mathrm{P}=0.198$

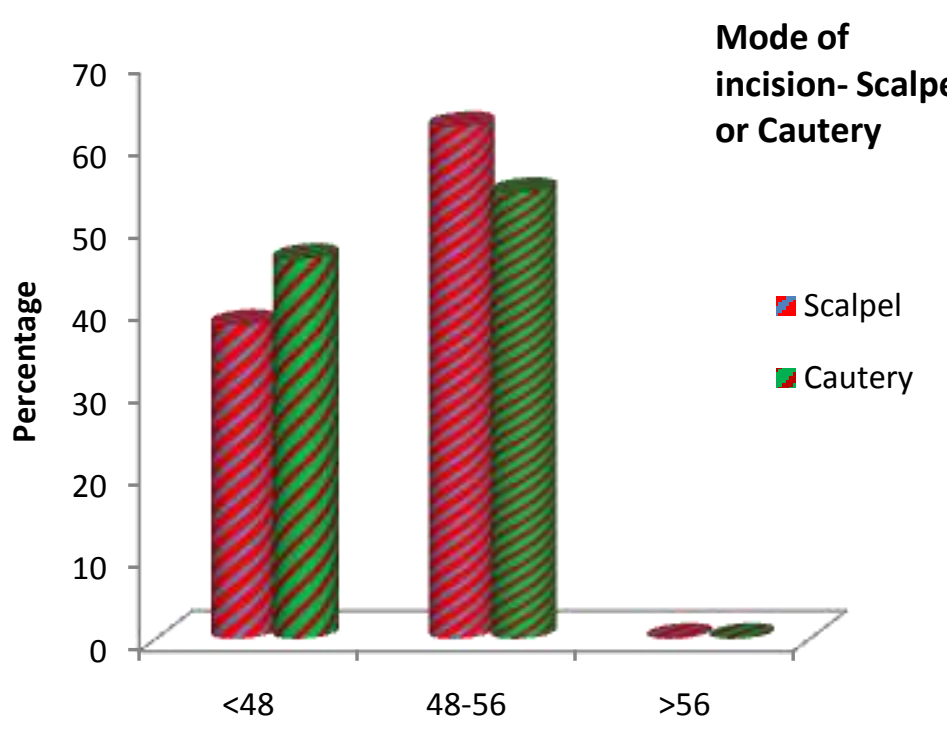

Duration of operation (in minutes)

Figure 1: Graph showing comparison of operating time

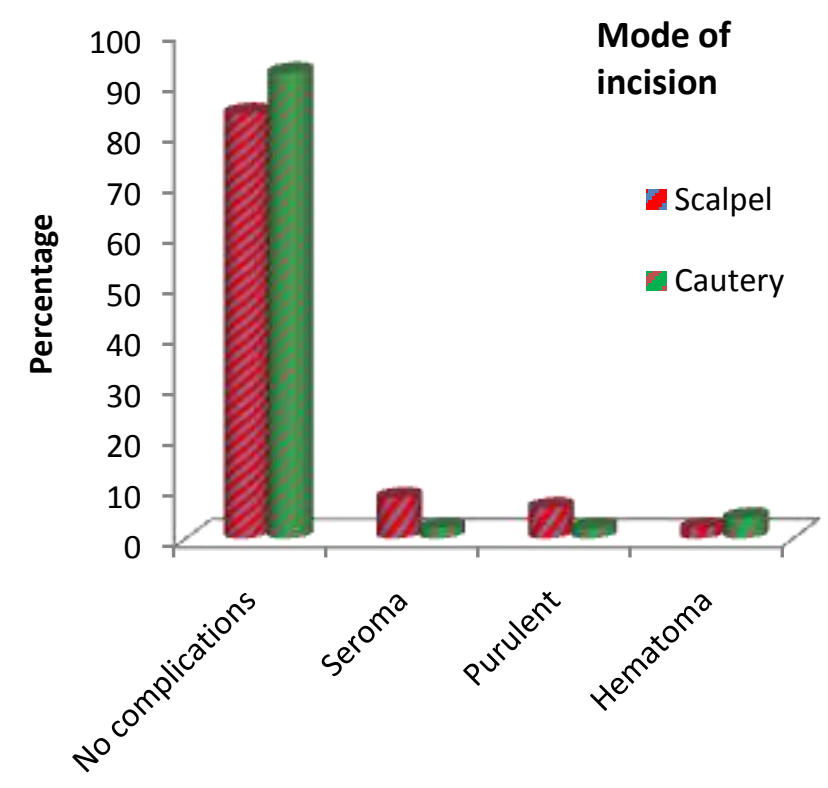

Post-operative complications- None, seroma,hematoma or purulent

Figure 2: Graph showing comparison of post-operative complications 


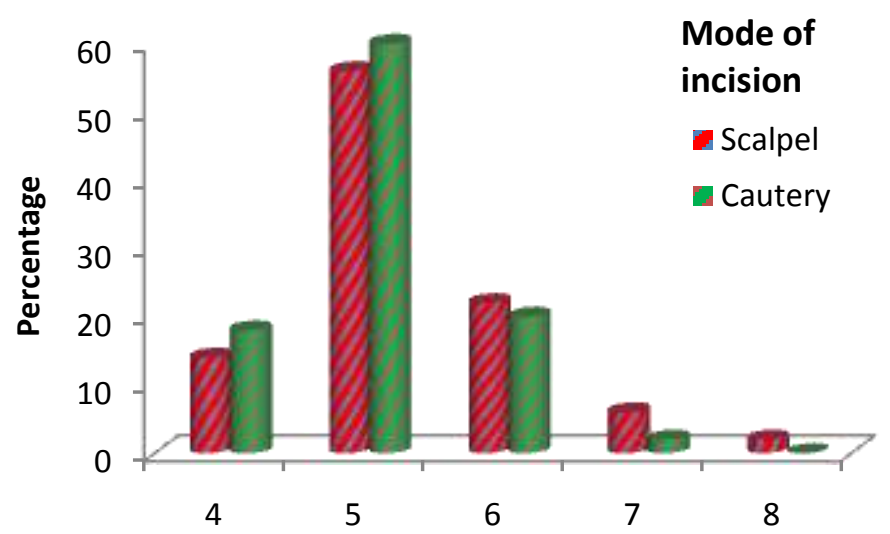

Post operative hospital stay (in days)

Figure 3: Graph showing comparison of post-operative hospital stay

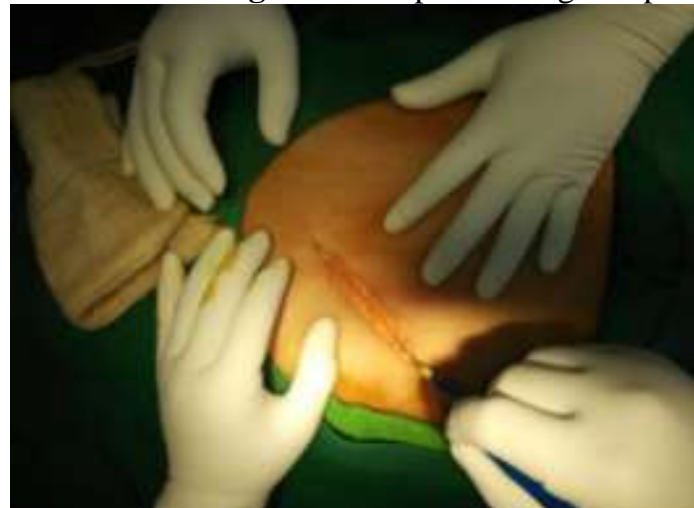

Figure 4: Skin incision with cautery

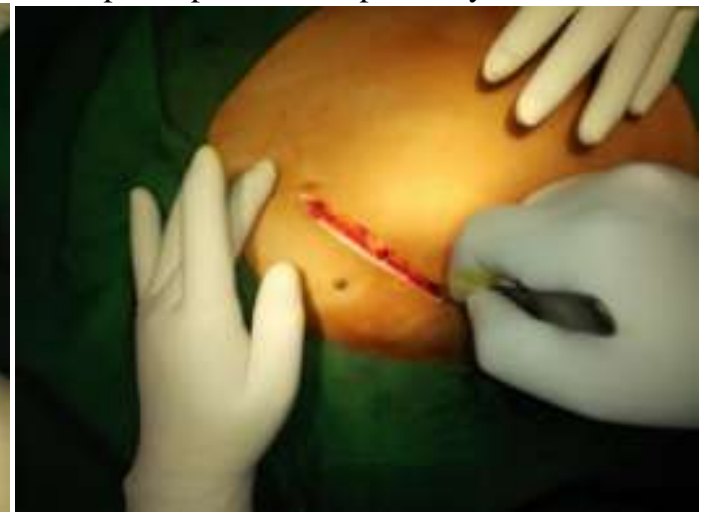

Figure 5: Skin incision with scalpel

\section{Discussion}

With the progress in the field of surgery, newer and better instruments and operating techniques are being developed rapidly. However making skin incision is one of the few things that have remained largely unchanged. An ideal method of skin incision which would provide a adequate and rapid exposure, minimum blood loss and a clean and cosmetically acceptable wound is every surgeons desire. Most of the surgeons at present use scalpel for making skin incisions. Electrocautery is used primarily for hemostasis and sparingly for skin incision.

This reluctance to incise skin with diathermy is partly attributable to the belief that electrosurgical instruments increase devitalized tissue within the wound, which consequently leads to increased wound infection, increased scar formation and delayed wound healing. Early studies with primitive diathermy machines suggested that electrosurgical incisions were associated with such charring and poor wound healing. ${ }^{7}$

Some studies also reported that electrocautery results in an increase in infections, indurated margins, and weakness of the cut wound when compared with scalpel. ${ }^{8}$ Other studies have demonstrated similar or decreased infection rates with the use of electrocautery. ${ }^{9,10}$ However, with the use of newer electrosurgical instruments, majority of the studies showed electrocautery skin incision to be equal to or better than scalpel in terms of time taken for incision, less blood loss, less painful and similar wound healing rates. ${ }^{9,11-14}$

Kearns SR et al $^{9}$ demonstrated a significant advantage for the use of electrocautery in creating midline abdominal incision over scalpel in terms of less blood loss, operating time, postoperative pain and analgesic requirements, and wound complication rates. Shivagouda $\mathrm{P}^{3}$ et al showed that electrocautery can be safely used in making skin incisions as results are comparable in two groups. The study found that the postoperative pain, postoperative analgesic requirements and complications were similar in the two groups.

\section{Conclusion}

Electrocautery is a safe alternative to steel scalpel for making abdominal skin incisions during routine operations. It is comparable to steel scalpel with regard to operating time, postoperative complications and duration of postoperative hospital stay when used for making skin incisions during operations. 


\section{References}

[1]. M Farquharson, B Moran, Farquharson's textbook of operative general surgery. $9^{\text {th }}$ ed. Great Britain: Hodder Education; 2005 .

[2]. SRK Valluru, and K Babji, Cautery versus Scalpel: A study on surgical incisions. Int J Sci Stud 2015;2(10):70-3.

[3]. P Shivagouda, BV Gogeri, AS Godhi, and SC Metgud, Prospective randomized control trial comparing the efficacy of diathermy incision versus scalpel incision over skin in patients undergoing inguinal hernia repair. Rec Res Sci Tech 2010;2(8):44-7.

[4]. AR Dixon, and DFL Watkin, Electrosurgical skin incision versus conventional scalpel: a prospective trial. J R Coll Surg Edinb 1990;35(5):299-301.

[5]. WD Rappaport, GC Hunter, R Allen, S Lick, A Halldorsson, T Chvapil, et al, Effect of electrocautery on the healing of midline laparotomy incisions. Am J Surg 1990;160(6):618-20.

[6]. SN Allan, S Spitz, R van Noort, and MM Black, Comparative study of scalpel and electrosurgical incisions on subsequent wound healing. J Pediatr Surg 1982;17(1):52-4.

[7]. JL Glover, PJ Bendick, and WJ Link, The use of thermal knives in surgery: electrosurgery, lasers, plasma scalpel. Curr Probl Surg 1978;15(1):1-78.

[8]. PW Soballe, NV Nimbkar, I Hayward, TB Nielsen, and WR Drucker, Electric cautery lowers the contamination threshold for infection of laparotomies. Am J Surg 1998;175(4):263-6.

[9]. SR Kearns, EM Connolly, S McNally, DA McNamara, and J Deasy, Randomized clinical trial of diathermy versus scalpel incision in elective midline laparotomy. Br J Surg 2001;88(1):41-4.

[10]. G Groot, and EW Chappel, Electrocautery used to create incisions does not increase wound infection rates. Am J Surg 1994;167(6):601-3.

[11]. MS Duxbury, SM Blake, A Dashfield, and AW Lambert, A randomized trial of knife versus diathermy in pilonidal disease. Ann R Coll Surg Eng 2003;85(6):405-7.

[12]. NA Chowdri, NA Wani, AA Ganai, SH Naqash, GQ Peer, and QA Wani, Comparative study of electrosurgical and scalpel incision in general surgery. IJS 2002;63:308-10.

[13]. E Chrysos, E Athanasakis, S Antnakakis, E Xynos, and O Zoros. A prospective study comparing diathermy and scalpel incision in tension free inguinal hernioplasty. Am Surg 2005;71(4):326-9.

[14]. HS Pollinger, G Mostafa, KL Horold, CE Austin, KW Kercher, and BD Mattews, Comparison of wound healing characteristics with feedback circuit electrosurgical generators in a porcine model. Am Surg 2003;69(12):1054-60. 